\section{ECONOMICS

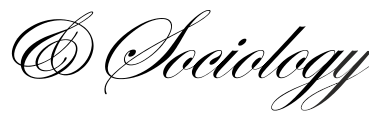

\author{
Aysen Ustubici \\ Koç University \\ International Relations Department \\ Turkey \\ E-mail:austubici@ku.edu.tr
}

\section{Darja Irdam}

The University of Cambridge

Department of Sociology

$U K$

E-mail:dirdam@ku.edu.tr

Received: November, 2011

1st Revision: January, 2012

Accepted: April, 2012

\title{
THE IMPACT OF REMITTANCES ON HUMAN DEVELOPMENT: A QUANTITATIVE ANALYSIS AND POLICY IMPLICATIONS
}

\begin{abstract}
This paper contributes to the discussions on the nexus between migration and development by assessing the effects of remittances on human development. We do so first through a quantitative approach, and second, by elaborating the findings of our quantitative analysis within a broader theoretical and policy framework. By using OLS, we measure the impact of remittances on human development and compare it with the effect of foreign direct investment (FDI) and official development assistance (ODA). The findings indicate that remittances have a positive correlation with the human development level and are indeed an effective way to enhance human development in countries with medium income, especially in the medium run. We demonstrate that remittances show divergent developmental effects in countries with different government approaches to migration. In the second part of the paper, we discuss different hypotheses about the causes of the problems that our findings reveal and compare different actual policy solutions found in the developing world. We argue that remittances have the most positive effect in terms of boosting human development in the countries where the state perceives migration as an effective labour export strategy.
\end{abstract}

JEL Classification: F22, F24, Keywords: migration studies, human development, effects of $\mathrm{O} 15$, remittances, quantitative analysis,

\section{Introduction}

The migration - development nexus has been discussed in social sciences from a variety of perspectives. Remittances, the money migrants send home, are the most tangible contribution of migration to home economies (Adams, 2003, p. 4; Skeldon, 2008, p. 3; Taylor et al., 1996, p. 181). The extent to which remittances are crucial catalysts empowering and speeding up human as well as economic development is widely scrutinized (De Haas, 2005; Jennings et al., 2005; Taylor et al., 1996, p. 181). Although perspectives from receiving end 
of migration dominate migration research ${ }^{1}$, incorporating perspectives from sending countries into migration research is a theoretical necessity (Nyberg-Sorenson et al., 2002, p. 18). The relationship between migration and national development has been discussed since 1960s; migration was considered a panacea for countries in the phase of development. With increasing number of people moving across international borders in the last two decades, the debate on migration and development has been revisited.

According to the World Bank statistics, in 2007, the amount of remittances in the world was 380 billion USD. This amount by three times exceeds the remittances in 1997 which were then around 119 billion USD (WB, 2009). ${ }^{2}$ The data also show that two thirds of these inflows were directed to middle income countries and middle human development countries and their share in total amount of remittances has steadily increased in the last decade (see Graph 1). It is striking that for more than a dozen countries including Jamaica, Tajikistan, Philippines, Senegal, Haiti, Liberia, Serbia, Lesotho and Nepal, remittances constitute more than 10 per cent of their GDP (WB, 2009).

The amount of remittances sent by migrants to their households back in the origin states worldwide has increased almost 45 fold and became a second largest source of foreign currency after FDI, which made remittances an pivotal area of attention for international institutions such as the World Bank and the UN (Aggarwal et al., 2006; Ratha \& Mohapatra, 2007). Recent studies on remittances have focused on their economic effects for migration sending regions and reached conflicting conclusions (Catrinescu et al., 2009; Chami et al., 2005). Although there is ethnographical evidence on the use of remittances for the enhancement of human capital at the community level (Cox et al., 2003; Goldring, 2003) - to our knowledge - no quantitative study has engaged in the cross-sectional analysis of the effects of remittances on human development.

The question gains relevance within a context where the amount of remittances received by developing countries is rising. Broadly speaking, there seems to be a correlation between middle income, medium human development, relatively high level of migration and relatively high level of remittances (Srinkandarajah, 2005, p. 29). The original dataset which we utilized for the quantitative analysis in this paper also confirms this relationship (see Graph 2 and Graph 3). Nevertheless, the question of whether a significant increase in remittances in the last two decades has been translated into an increase in human development indicators remains a puzzle. For the analysis, this paper uses HDI as a comprehensive, accurate and complex measure of socio-economic development (Sanderson, 2009, p. 6; Srinkandarajah, 2005, p. 30).

Within the context discussed above, the research addresses the following questions:

- Do remittances received by migrant sending countries have a positive impact on the overall level of human development? Are they more significant than other foreign currency inflows such as foreign direct investment (FDI) and official development assistance (ODA)?

- Under what circumstances are remittances more likely to affect human development positively? Do other variables such as existence of conflict, brain drain, net migration increase human development indicators?

- To what extent the impact of remittances differentiates among countries with very high, high, medium and low HDI countries?

\footnotetext{
${ }^{1}$ Sending country approaches tend to focus on issues such as integration, employment, security, multiculturalism rather than development of migrant sending countries.

${ }^{2}$ It should be noted beforehand that despite a steady grow in the amount of remittances received by migrant sending countries, the data by IMF and WB only counts formal transactions of remittances while it is believed that most of remittances are transferred by informal means (Maimbo \& Ratha, 2005, p. 6; Taylor et al., 1996, p. 181). Considering the difficulty of collecting aggregate data on informal remittances, this research will utilize the WB data on formal remittances.
} 
- What policy implications does the quantitative analysis lead us to in terms of maximize the beneficial capacity of remittances?

To answer these questions, the paper is organized in four sections: 1) we begin by elaborating on theoretical arguments on migration - development nexus and overview the empirical research measuring the effects of migration on different aspects of development. 2) In the data and method section, we explain the main independent, dependent and control variables used for analysis, the hypotheses attached to these variables, the data and the sample selection. 3) The following part summarizes the findings. 4) Finally we discuss the significance of remittances for human development under certain circumstances in countries with different development levels. Overall, we argue that remittances have a positive impact on changes in human development and they are more influential for human development than other foreign currency inflows such as FDI, ODA and exports. However, the beneficial use and effectiveness of remittances depend on the government strategies and the existence of encouraging and enabling policy environment.

\section{Theoretical Background}

The arguments in migration literature that remittances have a positive impact on human development relies on the theories based on the New Economics of Labour Migration (NELM) perspective which suggests that migration is a reliable strategy to negotiate the risks within both local and foreign markets (Massey et al., 1993, p. 436). This is especially true for developing countries where cash credits and public services such as health insurance are more costly and less available (Massey et al., 1993, p. 436). Remittances are crucial and often the only source of income for many households in developing countries. Migrants' remittances are well-known for their ability to reduce poverty (Ghai, 2005, p. 672; Gianetti et al., 2009, p. 290; King et al., 2009, p. 397). Remittances are vital means for survival of many households at home (King et al., 2009, p. 397; Marfleet, 2006, p. 91) and some states with very passive or fragmented state power survive solely thanks to remittances (Lindley, 2004, p. 485). Remittances, through poverty reduction lead to increase in the standards of living (Gianetti et al., 2009, p. 289; King et al., 2009, p. 391) including better nutrition and basic healthcare (Airola, 2007; De Haas, 2005, p. 1274; HDR, 2009, p. 72) which are crucial conditions for development (Jennings et al., 2005, pp. 688-689). These effects of remittances are reflected in the NELM perspective perceiving remittances as explicit family loans, when the expenses on migration are compensated by the positive impact of remittances on human development of the household (see for example Poirine, 1997). NELM perspective taking household as the unit of analysis is a suitable framework to explain the contuining role of emigrants in developing economies. In addition to that, remittances are most commonly transferred individually, so they do not face any political obstacles and go directly to population groups that are in desperate need of support. Furthermore, remittances can be the only sources of income and help for abandoned and politically or socially ignored people (Keely et al., 1989, p. 504; King et al., 2009, p. 391; Jennings et al., 2005, p. 689). For instance, remittances are the only connection of some remote rural areas of the developing countries to the global economies (Martin et al., 2004, p. 1545). Within this context, the ways in which workers' remittances are spent and invested in receiving countries gain significance.

As remittances are cash flows in foreign currency and reach high levels in certain contexts, they provide potential for national development. Based on literature and existing data, it is also suggested that remittances are better invested in human development in medium human development countries than in countries with low, high and very high HDI. This is because the share of remittances to GDP is higher in middle income countries (WB, 2009) and in such contexts remittances are less volatile than other foreign currency flows such 
as FDI, ODA or export-related flows (Sriskandarajah, 2005, p. 13). Since emigration rates from developed countries with high HDI level are relatively low, they receive fewer remittances. Given that countries with very high HDI have also well-developed markets, public benefits and private insurance systems (Massey et al., 1993, p. 436), remittances are not expected to have a significant impact on very high and high human development contexts. In countries with low HDI on the other hand, remittances are also less likely to have a significant positive impact on human development due to relatively smaller amounts of remittances received, internal failures of the state and the market (Massey et al., 1993, p. 436). This theoretical suggestion is also underpinned in the dataset that we generated for the empirical analysis as will be explained in detail in the discussion section.

It can be argued that the different ways in which existing incomplete data is used might lead to controversial results. However, such conflicting results also exist in ethnographic studies on the use of remittances and economic/human development. Most ethnographic research contend that remittances are mostly spent on consumption, daily needs and are not transferred into investment resulting in further employment opportunities for migration sending country population ${ }^{3}$ (İçduygu, 1998; Taylor et al., 1996, pp. 195-196). Nevertheless, their daily activities and households' everyday expenditure have long-term positive implications on development (Corona, Jimenez, 2009, p. 332). Furthermore, remittances contribute to enhance living standards in sending countries in many ways if, often times, not in the form of formal investment (De Haas, 2005, p. 1269). There is cross-regional evidence that an increase in family income results in better access to health services, education and social security (Goldring, 2003, p. 17), not to mention multiplier effects of these types of expenditure for the whole economy (De Hass, 2005, p. 1274; Maimbo \& Ratha, 2005 , p. 5). Besides, remittances in households receiving remittances (HRRs) increase the demand for domestically produced goods, thus they stimulate domestic economies a great deal (Adelman et al., 1990; Çiller, 1976, p. 172; Gianetti et al., 2009, p. 290). For many scholars, this is considered as an investment in human capital (Chimhow et al., 2005, pp. 8990; Sander \& Maimbo, 2005, p. 63). However, remittances are also invested in other projects which eventually contribute to HDI. Migrants' remittances are crucial sources of funding for construction and reconstruction of houses (Show, 2010, p. 22; Akuei, 2005, p. 2; Horst, 2004, p. 6; Corona, Jimenez, 2009, p. 340). Reconstruction ability is especially important in the lower income countries as these kinds of states have no funds to support reconstruction, and consequently, people have no chance to live in decent conditions.

In short, there is evidence that remittances enable human development at the community, local, and household levels as demonstrated in numerous case studies (Cox et al., 2003; Orozco, 2002). However, various structural factors including the socio-economic status of emigrants, existence of military conflict (Dessy \& Rambeloma, 2009, p. 23) influence the extent to which remittances are transferred to human capital. For instance, it has been argued that an increase in school enrolment caused by remittances inflows (HDR, 2009, p. 74; Ratha 2007; Cox et al., 2003; Yang, 2005; Hanson \& Woodruff, 2003; Airola, 2007; Gianetti et al., 2009, p. 290; Jones, 1998, p. 4; Taylor et al., 1996, p. 403; Martin et al., 2004, p. 1556; Durand \& Massey, 1996, p. 435; Horst, 2004, p. 8) correlates with decrease in child labour (Dessy \& Rambeloma, 2009, p. 2), therefore remittances highly contribute to human development.

However such interest towards celebrating remittances as "new development mantra" was not welcomed without suspicion especially regarding its effect on economic development in emigration countries in terms of dependency, brain drain and rising inequalities. The literature review reveals a complex and context-specific interrelationship between remittances

\footnotetext{
${ }^{3}$ Remittances sent to Turkey are also used as an empirical example of this phenomenon.
} 
and development (UNDP, 2009, p. 71). It is obvious that the migration or remittances by themselves do not cause development or dependency, but the effects of remittances in terms of human development occur in the long run and they are dependent on structural factors. To understand this relationship, conducting a cross-sectional analysis based on an original dataset on remittances and human development is the task ahead. To assess these long term results, there is certainly a need for rigorous data and research on the effects of remittances (Maimbo $\&$ Ratha, 2005, p. 15). At this point, research on human development in the least developed remittance receiving countries (Sanderson, 2009) and the role of remittances in development, poverty reduction (Adams \& Page, 2005; Chimbowu et al., 2005) and the impact of FDI on human development (Sharma \& Gani, 2004) have been exemplary for the model specification of this research. Both research measure human development as the dependent variable and lagged independent variables.

\section{Quantitative Analysis}

\section{Data, Hypotheses and Method of Measurement}

As the theoretical discussion reveals, the effects of remittances are more likely to be measured by household or community level studies (Cox et al., 2003; Orozco, 2002). However, there is also a number of cross-sectional quantitative studies (Adams and Page, 2005; Chimbowu et al., 2005). The hypotheses and the choice of variables in this research are derived from these exemplary studies. In this sense, we believe that this paper provides an opportunity to test the impact of remittances on development with a particular focus on human development by using the aggregate indicators of human development index (HDI) between 1990 and 2005. To this end, we also control for the influence of various other factors, such as foreign direct investment, official development assistance and public expenditure on education and health which are likely to affect human development.

\section{Definition and Measurement of Variables and Hypotheses}

\section{Dependent Variable}

The research takes the HDI as the main dependent variable. HDI measures the national achievements in human development based on three essential components of human life (Sanderson, 2009, p. 6). The index is composed of "average achievement in three basic dimensions of human development: a long and healthy life, access to knowledge and a decent standard of living" (UNDP, 2009, p. 210). The main dependent variable in the analysis is based on the percentage change in human development indicators in five-year periods between 1990 and 2005. In other words, three observations are made for each country to measure the change from 1990 to 1995,1995 to 2000 and 2000 to 2005. Data on HDI is compiled from UNDP 2009 Human Development Report (2009, pp. 167-170). ${ }^{4}$

There are also alternative models where we take HDI itself as the dependent variable. The data in this cluster will be measured at three observation points (t): 1995, 2000 and 2005 to measure the impact of lagged independent variables pertaining to $(\mathrm{t}-5)$. In the same vein with percentage change in HDI, we use percentage change in GDP per capita as an alternative dependent variable to measure the impact of remittances only on economic development. The data is compiled from a dataset based on WB World Factbook ${ }^{5}$. For this variable, instead of

\footnotetext{
${ }^{4}$ For the missing indicators of Haiti, Pakistan and Germany for 2000, we are using the indicators pertaining to 2001; and Ethiopia's missing data of 1990 is replaced with the data of 1991.

${ }^{5}$ The dataset is available at [http://gsociology.icaap.org/data/PD-Data2.xls].
} 
observations in 2005, we used GDP per capita pertaining to 2002 which is the latest year available in the dataset. ${ }^{6}$

\section{Independent Variables}

\section{Variables Measuring Foreign Currency Flows to Migrant Sending Countries}

As remittances constitute less than 2\% of GDP in most of the countries (WB, 2009), it is necessary to compare the effects of remittances on human development with other factors which are likely to influence human development (Sanderson, 2009). In this cluster, along with the share of officially recorded remittances in GDP, two additional variables are taken into account to avoid overestimation of the impact of remittances on human development. These variables are the percentage of FDI to GDP and the percentage of foreign aid to GDP. The reason for choosing these variables lies in the fact that these two constitute other foreign currency flows into sending countries; FDI and ODA are the currency flows, which in the recent years have been mostly compared with remittances in the academic and policy research (Dessy \& Rambeloma, 2009; Aggarwal et al., 2006).

1) Workers' remittances as a percentage of GDP.

Official migrant workers' remittances are defined as the sum of migrants' recorded monetary transfers to their countries of origin (UNDP, 2009, p. 212). Although it is believed that most of the remittances are transferred by informal means and therefore remain unrecorded; the data in this research are based on the official yearly records taken from WB's World Development Indicators (WDI) database. The records represent the amount of remittances reported by countries in their balance of payments (Catrinescu et al., 2009, p. 9). Rather than the amount or growth rate of remittances in USD, their percentage to the GDP of the country is taken into account to render the data more cross-nationally comparable. This choice relies on the measurement of remittances in Catrinescu et al. (2009, p. 5). As remittances directly reach families, it is hypothesized that they are more likely to be spent on enhancing human capital, for instance on basic needs, education, access to social services and healthcare, as opposed to FDI and ODA.

As the null hypothesis is that remittances of emigrants do not play a role in the change of human development indicators of the migration sending country, the research investigates whether and how remittances have a positive impact on the enhancement of human capital in migrant sending states.

H1a: Remittances positively contribute to the enhancement of human capital therefore, they have a positive impact on the level of change in HDI.

H1b: The impact of remittances on human development is more significant in countries with medium HDI.

2) Foreign direct investment as a percentage of GDP.

FDI refers to private capital inflows into a foreign country into the form of productive assets where the operations of the investor are legally controlled (Sanderson \& Kentor, 2009, p. 533). FDI is believed to highly contribute to the economic and human development of the country (Sharma \& Gani, 2004). However, it is almost a consensus in the remittances literature that in most of the developing countries, remittances stand as a more reliable source of foreign currency inflow than foreign direct investment (Maimbo \& Ratha, 2005; NybergSorenson et al., 2002; UNDP, 2009). In this sense, the percentage of FDI to GDP will serve as a control variable to compare the impact of FDI on human development to that of remittances. FDI is considered as a signifier for integration with the global economy.

\footnotetext{
${ }^{6}$ The observations for Armenia, Kazakhstan and Belarus in 1990 are missing.
} 
Remittances are more effective on human development in countries where FDI flows are relatively low or unstable (see for example Aggarwal et al., 2006). In this sense, integration of the national economies with the global capital flows may lessen the importance of remittances for economic and human development. In this sense, less impact is expected for high human development countries, considering that high human development levels correlate with high economic development, hence more integration with global capital flows.

H2a: The effect of FDI on HDI is expected to be more significant than that of remittances in countries more integrated with the global capital (taken as high human development countries).

$\mathrm{H} 2 \mathrm{~b}$ : In countries with medium and low human development, the impact of remittances on HDI is more significant than that of FDI.

3) Foreign aid as a percentage of GDP (if applicable).

Foreign aid is considered as another dimension of foreign currency inflows into a country. For this research, we are going to use the ODA records by WB to measure the percentage of foreign aid to the GDP of the country. ODA is "grants by official agencies of the members of the Development Assistance Committee (DAC), by multilateral institutions and by non-DAC countries to promote economic development and welfare"7 (UNDP, 2009, p. 211). In principle, ODA is allocated to social services including health services and education.

H3: ODA is likely to have a positive impact on human development more than FDI and remittances in contexts where remittances and FDI remain relatively low ${ }^{8}$.

\section{Data}

The numerical variables above are taken into account to compare different sources through which foreign currency flows into a country. The data on the variables explained above were compiled from WB World Development Indicators available online. ${ }^{9}$ As the variables were measured in USD rather than in terms of their share in the GDP, we had to calculate all remittances, FDIs and ODAs as a percentage of the countries' GDP in 1990, 1995, 2000. However, the data on remittances in 1990 are missing for certain countries, namely, Denmark, Japan, Poland, Kazakhstan, Belarus, Armenia and Nicaragua. Remittances in 1990 are replaced by the corresponding values of 1991 for Denmark and Japan, 1992 for Nicaragua, and 1994 for Poland. Nevertheless, the data remained missing for Kazakhstan, Belarus and Armenia, since most of the post-Soviet countries lack systematic data on remittances until 1995. These inputs are kept as missing variables. Regarding FDI and ODA, there are four observations where we had to insert data pertaining to other periods different from the rest of the dataset. These countries are again Kazakhstan and Belarus, where we had to insert data from 1991 and 1992 for FDI and ODA. All these three variables, remittances, FDI and ODA are expected to have a positive impact on human development and they will be tested against each other.

To measure their impact on human development, the above variables are used as lagged variables. This is to say that percentage of remittances, FDI and ODA to GDP at the year $t$ will be compared to the changes of human development indicators of the country from year $t$ to $t+5$. More concretely, the data available on these above variables in 1990, 1995 and 2000 are evaluated along with the changes in human development indicators in the previous five years: 1995, 2000 and 2005 respectively. Remittances require some time to be spent by

\footnotetext{
${ }^{7}$ For more details see [www.oecd.org/dac/stats/daclist $]$.

${ }^{8}$ The impact of ODA on HDI is expected to be insignificant in very high and high human development countries.

${ }^{9} \mathrm{http}: / / \mathrm{ddp}-$-ext.worldbank.org/ext/DDPQQ/member.do?method=getMembers\&userid=1\&queryId=135.
} 
the household in a particular way which can have its impact on human development. Therefore, we need to account for these partcular time periods.

\section{Control Variables Measuring Domestic Factors}

4) Emigration.

In the absence of complete data on migrant stock abroad ${ }^{10}$ as a share of population, we used net emigration numbers as a dummy variable. In other words, this dummy variable takes the value of 1 for the emigration countries where emigrants outnumber immigrants and 0 for the immigration countries. As with other variables, three observations are made for each country in 1990, 1995 and 2000.

5) Brain Drain.

In this research, brain drain measures the percentage of migrants with tertiary education to the total number of citizens with similar degrees. The data for 2000 are compiled from WB (2008). Beine and Docquier provide an appropriate data for 1990, however, they exclude high income countries. This significantly reduced the number of observations on brain drain.

Studies show that brain drain does not only result in the emigration of the best educated among the population, but also this segment of the population is more likely to integrate in the receiving society, therefore to remit less (Beine \& Docquier, 2006; Skeldon, 2008). Although the effect of braindrain on remittances can still be positive, it clearly has negative implications on the human development through other factors such as outsorcing of professionals and highly-skilled labour. Therefore, a number of empirical research also reveals that countries where the human development is negatively affected by brain drain are those which are small in population size and highly impacted by the emigration of the skilled (Beine \& Docquier, 2006; Dessy \& Rambeloma, 2009).

$\mathrm{H} 4$ : Brain drain is not expected to have a significant impact on changes in HDI but it is expected to reduce the significance of remittances.

6) Conflict.

This variable is included considering that the existence of internal or external conflict reduces the impact of remittances on human development. In such cases, remittances can be channelled to support conflicting groups rather than to get access to social services (NybergSorenson, 2002, p. 23). The data is obtained from MEPV ACTOTAL datasets measuring the summed magnitudes of all civil and interstate conflict. The variable takes values between 0 and 6 depending on the average magnitude of conflict in the five-year periods between 19901995, 1995-2000 and 2000-2005. ${ }^{11}$

H5: It is hypothesized that the existence of conflict will have a negative impact on the HDI.

7) Democracy.

The data on the level of democracy based on the Polity II dataset may help us to test whether democracies are more likely to transfer remittances into human development. For five-year periods of observation, the average of the Polity II data is taken into consideration. In other words, as in the Polity II dataset, a scale from -10 to 10 is used.

8) Population.

Population of the country may also have an impact on the analysis in the sense that small states are more likely to be outliers in matters such as brain drain or migrant stock

\footnotetext{
${ }^{10}$ Migrant stock abroad is defined as "the estimated number of international migrants, expressed as a percentage of the total population" (UNDP, 2009, p. 211).

${ }^{11}$ Here, we deliberately used the level of internal and external conflict rather than using conflict as a dummy variable because the latter is correlated with the public expenditures.
} 
abroad. For big and more populated countries on the other hand, it might be difficult to measure the overall impact of remittances on human development.

9) Public expenditure on health and education as a percentage of GDP.

The variable indicates the sum of public expenditure on health and education by all levels of government (UNDP, 2009, pp. 210, 211) as a percentage of GDP. Percentage of public expenditures to GDP is another factor that directly affects human development in a country. As in the case of FDI and foreign aid, measuring public expenditures helps us not to overestimate the impact of remittances on human development. To this end, the percentage of public expenditure to GDP is compiled from UNDP 2006, 2009 and earlier human development reports of UNDP. There are a number of observations where the data are missing and replaced by data pertaining to the previous or following years if available.

10) Military expenditure.

Military expenditure is considered as an unproductive governmental expenditure in terms of human development (Sharma \& Gani, 2004, p. 9). The data is compiled from WDI and does not contain any observations for Haiti and Costa Rica.

H6: Public expenditure is expected to have a positive impact on the change in HDI whereas military expenditure is expected to have a negative impact on the change in HDI.

11) Exports.

This variable indicates the total amount of exports to GDP and its data are compiled from the WDI. It is considered as another foreign currency source for countries.

12) GNI per capita PPP.

The gross national income per capita is used as a control variable when the dependent variable is HDI or percentage change in HDI because unlike GDP, GNI is not a component of HDI. The data is compiled from WDI database.

\section{Sample Specification and Method}

As explained above, it is hypothesized that remittances sent at year $t$ are likely to make a positive contribution to human development at year $t+5$; assuming that there is a continuation in the reception of remittances. To this end, lagged endogenous variables are used on the right side of the equation. In other words, almost all numerical independent variables are lagged including workers' remittances, FDI, ODA, public expenditure, military expenditure, export, brain drain and GNI per capita. The dummy variable on the emigration is based on the existence of positive net emigration [emigration-immigration] for each observation.

As unit of analysis, the research takes three points of observation by each of the 32 randomly selected countries. Countries are chosen randomly from each cluster of WB economic development index based on GDP per capita PPP. These clusters are high income, upper middle income, lower middle income and low income. 8 countries from each cluster are randomly selected and the latest index was taken from WB 2008 development indicators. Consequently, 8 high income countries: Denmark, Austria, Germany, Japan, New Zealand, Israel, South Korea (Rep. of Korea) and Portugal, 8 upper middle income countries: Poland, Turkey, Mexico, Kazakhstan, Brazil, Malaysia, Costa Rica and Botswana, 8 lower middle income countries: Belarus, Peru, Namibia, Armenia, Jordon, Morocco, Sri Lanka and Nicaragua and 8 low income countries: Nigeria, Senegal, Pakistan, Haiti, Bangladesh, Rwanda, Ethiopia and Mozambique are included in the dataset. The random choice of countries is adjusted given the availability of the data. Regarding the geographical representation, Uruguay lacks data on remittances for instance and it is replaced with Mexico and Congo is replaced with Mozambique. The random sample includes countries from all regions of the world, therefore it is geographically representative. As the dataset contains data 
measured at five-year intervals over the period 1990-2005, overall $32 * 3=96$ observations are included. However, due to the lack of data at certain observations, the models include at most 88 observations. As the dependent variable is continuous, ordinary least squares (OLS) and multiple regression analysis is used for estimation.

\section{Findings and Discussion}

\section{Multiple Regression Analysis of the Sample}

Table 1 presents the results of the multiple regression analysis on the effects of remittances on development for four different dependent variables, measuring human development and economic development. The former is measured by HDI and percentage change in HDI over 5 years, the latter by GDP per capita and percentage change in GDP per capita over 5 years (see Table 1 in Appendix 1).

The overall analysis for countries from different HDI clusters reveals that remittances have a positive impact on percentage changes in HDI. Models 3, 4, 5 and 6 in Table 1 indicate that remittances are the most significant of the factors positively affecting percentage changes in HDI. Accordingly, one unit of increase in the ratio of remittances to GDP results in .201 unit increase in percentage change in HDI when controlled for FDI, ODA, public expenditures, conflict and democracy (Model 3). The coefficient for remittances is still significant but it is reduced to .158 in Model 4 when controlled for population, military expenditure, export and emigration and to .146 with GNI per capita as an additional control variable in Model 5. The hypothesis that remittances have a positive impact on changes in HDI (H1A) is confirmed. Including brain drain as an additional control variable in Model 6 not only increases the coefficient of remittances to .168, but also brain drain itself has a significant positive impact on percentage change in human development; though with a smaller coefficient equal to .055 . In the overall analysis, the hypothesis that the brain drain is not expected to have a significant impact on changes in HDI but is expected to reduce the significance of remittances $(\mathrm{H} 4)$ is rejected. We suggest that the brain drain can be correlated with the overall human development. Economically worse-off countries, unable to provide enough employment opportunities or attractive wages, are more likely to send their best educated and most skilled professionals abroad since it is relatively easier for them to find employment in the host country ${ }^{12}$.

While ODA is also significant and positively affects the percentage change in HDI in Model 3, the positive impact of FDI is insignificant across different models. This can be explained by the fact that FDI has a less direct impact on the enhancement of human capital than remittances which reaches households without mediation. As expected, conflict is a significant factor that negatively effects the changes in HDI which also confirms H5.

What is particularly curious in this regression analysis is the significant negative effect of the share of public expenditures to GDP on the change in HDI. However, this does not indicate that public expenditure does not influence or negatively influence HDI per se. To explain this nuance, we also included HDI itself as a dependent variable (Model 1 and 2) where public expenditures and democracy have a significant positive impact on HDI itself. Also, ODA is significantly and negatively correlated with HDI because countries receiving high levels of ODA are the ones with lowest levels of HDI.

Since we are dealing with percentage changes in HDI here, the negative coefficient of the public expenditure variable could be interpreted as the following: in countries where public expenditures are high, the percentage increase in HDI is less because these countries

\footnotetext{
${ }^{12}$ This result should be tested on a more inclusive dataset containing more country cases.
} 
are already at the upper echelons of the human development scale. However, the finding that public expenditure does not have a positive effect on changes in HDI rejects our hypothesis (H6) regarding the positive impacts of public expenditure on changes in HDI. The interaction between public expenditure, migration and HDI will be discussed in more detail in the paper section dedicated to the suggested policy implications.

Overall, models based on percentage changes in HDI seem to affirm the theory on remittances as implicit family loans (Poirine, 1997). This theory, based on NELM perspective states that remittances are used to increase the long term benefits of migration through investments in the human capital of non-migrant members of the household.

\section{Multiple Regression Analysis across Human Development Clusters}

It should be noted that the findings explained above include all 32 countries in the sample regardless of their human development level. Further regression analyses are run to capture the differences among groups of countries clustered by the human development level.

UNDP differentiates four clusters of countries based on their human development levels:

Very high human development countries (HDI> 897) (18 observations).

High human development countries $(800<\mathrm{HDI}<897)$ (13 observations).

Medium human development countries $(499<\mathrm{HDI}<800)$ (35 observations).

Low human development countries $(\mathrm{HDI}<499)^{13}(15$ observations).

Based on these observations and theoretical background discussed in the literature review, a curvilinear relationship between remittances and different HDI levels is assumed Table 2 reiterates the regression by clustering countries in four groups: very high/high, medium/low, medium and low human development. As expected, remittances have a positive coefficient but they are not significant for countries with high and very high HDI. On the other hand, in medium and low human development countries taken together, remittances do significantly increase the percentage changes in HDI.

Accordingly, the positive impact of remittances on percentage changes in HDI is most significant for countries with medium HDI than countries with low, high and very high HDI. As HDI and income have a positive linear relationship (see Graph 4), the similar curvilinear model is also assumed to be more significant for upper and lower middle income countries than for high and low income countries.

Within this context, the models in Table 2 are specified to test the hypotheses $\mathrm{H} 1 \mathrm{~b}$ on the more significant effects of remittances on HDI for countries with medium HDI, H2a and $\mathrm{H} 2 \mathrm{~b}$ on the differentiated effects of FDI across different human development clusters (Sharma \& Gani, 2004) (see Table 2).

The regression results show that the effect of remittances is most significant for medium human development countries. Accordingly, one unit increase in the ratio of remittances to GDP results in .148 unit change increase in the percentage change in HDI for countries with medium HDI. Therefore, H1b is confirmed. However, unlike what is suggested in $\mathrm{H} 2 \mathrm{a}$ and $\mathrm{H} 2 \mathrm{~b}$, FDI has a significant impact on percentage changes in HDI only for medium development countries. Therefore, the hypothesis H2a suggesting that FDI positively affects HDI in countries with very high and high HDI is rejected. Also, H2b is partly rejected because FDI has a more significant impact on percentage changes in HDI in countries with medium HDI.

FDI is statistically proven to be mostly channelled to the medium income countries across the world (Gammeltoft, 2002). This can be explained by the relatively cheap and

\footnotetext{
${ }^{13}$ Human development clusters are based on 2005 HDI which is the latest year of observation for HDI.
} 
abundant labour in the medium development states, but at the same time relatively developed infrastructure and financial and political stability that low income countries usually lack. Therefore, since both FDI and remittances enhance human development, more attention needs to be paid to attracting and managing both of these financial flows in the middle income countries as a state strategy for development. ODA, on the contrary, does not have significant positive impact on changes in HDI in none of the clusters. Therefore, H3 is rejected.

Unexpectedly, there is a significant negative relationship between workers' remittances and percentage changes in low HDI countries. Particularly, in countries with low HDI, despite the negative coefficient of workers' remittances, there is a positive correlation between percentage changes in HDI and emigration. Accordingly, in low human development countries where emigration exceeds immigration, there is a 10 unit of increase in the percentage change in HDI. This might be explained by the fact that the outflow of labour eases the pressure on the labour market back home and at the same time gives the migrant workers a chance to earn income for their families. However, it is also necessary to account for the brain drain effect, which can negatively affect the home economy leading to severe lack of expertise and highly-skilled labour, which altogether will inevitably result in decrease in HDI. In order to provide more solid explanations, more research with particular emphasis on low HDI migration-sending states is needed.

Given the limitations of put data, the negative correlation between remittances and change in HDI in low HDI countries can be explained in two ways As shown in Table 2, in countries with low human development where workers' remittances are not that high at the first place Secondly, low HDI countries are more prone to conflict than others. And conflict significantly and negatively affects the percentage changes in HDI. Therefore, in conflict situations where HDI is already low, it is less likely that remittances will be invested in order to increase human capital as implicit family loan theory of remittances suggests. Therefore, $\mathrm{H} 5$ on conflict is confirmed also for countries with low HDI levels.

Public expenditure seems to be negatively correlated with HDI in medium/low and medium HDI states. As public expenditure is not explored as a separate variable in this model, finding out if it is a spurious effect or a substantial finding would require further research. Unsurprisingly, the model demonstrates that conflict has a negative effect on HDI. Democracy, as the model suggests, is also negatively correlated with HDI in medium HDI countries. In order to explain the mechanisms behind the interaction of these three variables and HDI different statistical models need to be utilized. This, however, lies beyond the scope of this paper.

\section{Policy Implications for Successful Management of Remittances for Human Development}

Even though the quantitative analyses reveal that remittances are likely to contribute to human development especially in developing countries, a closer cross-country investigation unfolds that not all countries equally benefit from savings sent by their emigrants abroad. At this point, policies pursued by states towards remittances and whether remittances are invested at community or household level gain importance. In short, empirical analysis suggests that remittances are crucial to national economies in emigration countries but as migration is an issue requiring policy (İçduygu, 2010), governments have to pursue certain strategies to maximize the beneficial effect of remittances. The policy suggestions outlined below are based on the literature as well as on the findings of our quantitative analysis.

\section{Governments have to improve investment climate}

As remittances reduce liquidity constraints and increase savings dramatically (Corona Jimenez, 2009; Gianetti et al., 2009) they contribute greatly to economic activities and 
productive investment (Abadan-Unat et al., 1993; De Haas, 2005; Koç \& Onan, 2004; Martin et al., 2006; Ratha \& Mohapatra, 2007; Taylor, 1999) under certain circumstances. First, it is the government's responsibility to create a favourable investment environment for the HRRs (Orozco, 2002, p. 55; Taylor et al., 1996; Taylor et al., 1996b; Jones et al., 2007, p. 28). For instance, in the Philippines, the government introduced small-denominated treasury bonds to ensure workers' savings abroad (Martin et al., 2004). Similarly, information on the investment possibilities in the home economies has to be more available to HRRs (Ratha et al., 2007). Second, credit opportunities that the state provides to migrants' households need to be significantly improved (Orozco, 2002; Jones et al., 2007, p. 28). To illustrate, due to the absence of credit opportunities, Tajikistan with huge rates of labour emigration (remittances constitute up to $50 \%$ of Tajikistan's GDP) has so far failed to insure productive investment of the remittances in agriculture and business (Kireyev, 2006; Olimova \& Bosc, 2003). Third, the policy of matching funds is a very important guarantor of success for transnational investment especially in developmental projects (Orozco, 2002, p. 61; Taylor et al., 1996b, p. 403; Çiller, 1976, p. 181; UN, 2006) and it has demonstrated remarkable success for example in Mexico (HDR, 2009, p. 81; Brinkerhoff, 2009). Fourth, it is important to provide entrepreneurial education and training for the labour migrants (Mughal, 2007, p. 155). Finally, remittances provide a possibility for people to purchase land (Ahmed, 2000; Jones, 1998, p. 4; Taylor et al., 1996, p. 403), agricultural equipment (Gianetti et al., 2009, p. 291) and tools as well as they can improve their agricultural infrastructure (Durand \& Massey, 1996, p. 431) which gives HRRs a chance to deal with non-commercial or even commercial agriculture. As an illustration, Durand \& Massey (1996) claim that about 20 per cent of rural enterprises in Mexico are sponsored by remittances. In addition to that, higher incomes of households receiving remittances increase the demand for agricultural production (Taylor et al., 1996, p. 200). Therefore, it is necessary to improve the available agricultural technology to ensure effective investment of remittances in agriculture (Kirwan, 1981, p. 692). Investment of remittances in agriculture can lead to industrial decentralization and revitalization of regional economies (Papademetriou, 1985) and to positive changes in normally oversaturated urban market (Çiller, 1976). It is often neglected in the academia however, that remittance investment is a very self-inducing process after a certain point. Migrants invest in their home countries because they intend to return and thus they try to create favourable conditions for themselves and their families. Therefore, migrants tend to invest even in the conditions of a very depleted home economy, conflict situation or high level of corruption at home. Migrants are actually the first to invest in those situations (Gillespie et al., 1999, p. 624). Very few scholars (for instance Ratha et al., 2007) actually emphasize that the information on the migrant investment at home must be available for the international investors to increase the incentives for their participation in economy., In short remittances might have a potential to make the country more attractive for international investors, or, at least, to solve some of the obstacles that prevent the international investors from bringing their capital in. It is pivotal, however, that migration-sending states do not fall into the trap of perceiving either FDI or remittances as a panacea for their economic problems related to development. Yet a strategic usage of the combination of the two can be very beneficial for development particularly in politically stable contexts free from conflict.

\section{Governments should inform and educate households about how to manage remittances}

On the microeconomic level, to reinforce the benefits from remittances in the poorer households, it is necessary to make the inflow of remittances stable while maintaining the domestic source of income (Show, 2010, p. 18). Thus, remittances should be perceived as diversification of income, as additional income and not as the only source of liquidity for the 
households. Households should improve or maintain their everyday activity. Large inflows of remittances in uneducated families in developing countries are often said to create liquidity euphoria when people start wasteful consumption and purchasing alcohol and drugs. In these cases, education and training of the migrants' families is usually seen as a solution (Show, 2010 , p. 27). To prevent wasteful consumption, households should be well informed about how to act when they receive inflows of remittances from abroad. Special education which can be provided by societal courses, lectures or consulting agencies can help achieve the necessary level of information that will help families in developing states to take advantage of migration and reduce its negative aspects. The success of this information-oriented policy can be seen in the Philippines (Martin et al., 2004).

\section{Remittances should be used as auxiliary means and not as a substitute for public expenditure}

In many developing countries with robust migration, the governments often fall into the trap of seeing remittances as the final means of development, thus very often the state tries to avoid its responsibilities as a public goods provider. It is proved that the HRRs spend more on healthcare (Corona, Jimenez, 2009; Gianetti et al., 2009; Jennings \& Clarke, 2005). However, remittances can be much more efficient and beneficial for the home economy when they are invested in productive activity rather than in healthcare (Corona, Jimenez, 2009, p. 333). Similarly, education is given more attention in the families of migrants (Gianetti et al., 2009, p. 290; Jones, 1998, p. 4; Taylor et al., 1996, p. 403; Martin et al., 2004, p. 1556; Durand \& Massey, 1996, p. 435; Horst, 2004, p. 8). Remittances in some cases were also used for the schooling and professional training of local communities at home (Horst, 2004, p. 8). Finally, UN development report emphasizes that the level of education is often much higher among migrants than among the local people in the developing countries (HDR, 2009, p. 64). However, similarly to the case of healthcare, remittances can be more effective if they contribute to investment in production or labour-intensive industries. Therefore, public services such as education and healthcare should be primarily provided by the government, while remittances should be used in the ways which contribute to economic development. As our research demonstrates, despite the debatable effects of public expenditure on the changes in HDI, remittances can be successfully used by the governments to enhance the development potential of the public expenditure. As it can be seen from the models 1 and 2 summarized in Table 1, very high and high human development states usually have substantial share of their budgets allocated to public expenditure. Therefore, it can be suggested that more state provision of public goods and services combined with good governance approach can be recommended as a successful strategy for the migration-sending states to take advantage of migrants remittances for their human development. Most importantly, in addition to basic public services, migration-sending states are recommended to pay special attention to establishing easier migration regimes fostering circular migration and easing official remittance transfers as well as increasing investment opportunities for migrants (De Haas, 2005; Orozco, 2002; Shaw, 2010). Migration literature, in fact, provides discussions on the ways that the states can use to channel both public expenditure and remittances to significantly contribute to their overall human development (see for example, Orozco, 2002; Taylor et al., 1996; Jones et al., 2007).

\section{Conclusion and Further Research}

Despite the fact that the nexus between migration and human development has been causing lively academic debate for several years, no sound attempt has been made to observe 
the impact of migration-associated foreign currency flows on human development in the migration-sending states. The article has bridged the academic and policy debates on the migration-development nexus with a small-scale statistical analysis measuring the impact of official flows of workers' remittances on the aggregate level of human development.

We have developed several quantitative models for measuring the impact of remittances and other flows of foreign currency on the level of human development in different countries. We have found that the overall impact of remittances on both relative and absolute changes in HDI is very significant. Remittances prove to have a higher explanatory power than other competing explanations such as ODA, FDI and public expenditure. As expected, the intensity of domestic and international conflict is negatively correlated with changes in HDI. Interestingly, FDI, which is considered as a primary engine of economic development in the global economy, is not significantly related to changes in HDI. Contrary to the expectations, the ODA independent variable does not have a significant effect on relative changes in HDI for low-income and low-human development countries.

When analysed through human development country clusters, it is evident that remittances are most influential in middle-human development countries as migration theory implies. Assessing both the findings of our model and evidence from policy discussions, we have come to the conclusion that in the medium run, remittances have a higher effect on human development in states where migration is approached as a labour-sending strategy and where certain policies such as investment management, household education and state provision of basic public goods are pursued.

\section{References}

Abadan-Unat, N.; Keleş, R.; Penninx, R.; Van Renselaar, H.; Van Velzen, L.; Yenisey, L. (1993), Migration and Development, Ankara: Ajans Türk Press.

Adams, R.H. (2003), International Migration, Remittances, and the Brain Drain A Study of 24 Labor-Exporting Countries, World Bank Policy Research Working Paper, 3069.

Adams, R.H.; Page, J. (2005), Impact of International Migration and Remittances in Poverty, in: Maimbo, SR. and Rahta, D. (eds), Remittances Development Impacts and Future Prospects, Washington: The World Bank, pp. 277-306.

Aggarwal, R.; Demirgüç-Kunt, A.; Martines Peria, M. S. (2006), Do Workers' Remittances Promote Financial Development? World Bank Working Paper.

Ahmed, I. I. (2000), Remittances and Their Economic Impact in Postwar Somaliland, Disasters, 24(4), pp. 380-389.

Airola, J. (2007), The Use of Remittance Income in Mexico, IMR, 41(4), pp. 850-859.

Akuei, S. R. (2005), Remittances as Unforseen Burdens: The Livelihoods and social obligations of Sudanese Refugees, Global Migration Perspectives, 18.

Appleyard, R. T. (1989), Migration and Development: Myths and Reality, IMR, 23(3), pp. 486-499.

Beine, M.; Docquier, F.; Rapoport, H. (2008), Brain drain and human capital formation in developing countries: winners and losers, Economic Journal, 118, pp. 631-652.

Brinkerhoff, J. M. (2009), Creating an Enabling Environment for Diasporas' Participation in Homeland Development, IOM, International Migration.

Chami, R.; Fullenkamp, C.; Jahjah, S. (2005), Are Migrant Remittance Flows a Source of Capital for Development? International Monetary Fund (IMF) Working Paper, No. 03/189, Washington.

Catrinescu, N.; Leon-Ledesma, M.; Piracha, M.; Quillin, M. (2009), Remittances, Institutions and Economic Growth, World Development, 37 (1), pp. 81-92. 
Chimbowu, A. O; Piesse, J.; Pinder, C. (2005), The Socio-Economic Impact of Remittances on Poverty Reduction, in: Maimbo, SR. and Rahta, D. (eds), Remittances Development Impacts and Future Prospects, Washington: The World Bank, pp. 83-102.

Ciller, T. (1976), The Economics of Exporting Labour to the EEC: A Turkish Perspective, Middle Eastern Studies, 12(3), Special Issue on the Middle Eastern Economy, pp. 173185.

Corona Jimenez, M. A. (2009), Household Development in Tlapanala: A Comparative Study Between Households Receiving Remittances and Households Not Receiving Remittances, Journal of Poverty, 13, pp. 331-349.

Cox, E.; Ureta, A.; Ureta, M. (2003), International Migration, Remittances, and Schooling: Evidence from El Salvador, Journal of Development Economics, 72, pp. 429-461.

De Haas, H. (2005), International Migration, Remittances and Development: Myths and Facts, Third World Quarterly, 26 (8), pp. 1269-1284.

Dessy, S.; Rambeloma, T. (2009), Immigration Policy, Remittances, and Growth in the Migrant-Sending Country, Cirpée, Working Paper 09-15.

Durand, J.; Massey, D. S. (1992), Mexican Migration to the United States: a Critical Review, Latin American Research Review, 27, pp. 3-42.

Gammeltoft, P. (2002), Remittances and Other Financial Flows to Developing Countries, International Migration, 40 (5), SI, pp. 181-211.

Ghai, D. (2005), How Can Kenyans Abroad Contribute to National Development? Development in Practice, 15 (5), pp. 668-676.

Gianetti, M.; Federici, D.; Raitano, M. (2009), Migrants Remittances and Inequality in Central-Eastern Europe, International Review of Applied Economics, 23 (3), pp. 289307.

Gillespie, K.; Riddle, L.; Sayre, E.; Sturges, D. (1999), Diaspora Interest in Homeland Investment, Journal of International Business Studies, 30 (3), pp. 623-634.

Goldring, L. (2003), Re-thinking Remittances: Social and Political Dimensions of Individual and Collective Remittances, CERLAC Working Paper Series, February.

Hanson, G. H.; Woodruff, C. (2003), Emigration and Educational Attainment in Mexico, San Diego: Mimeo, University of California.

Horst, C. (2004), Money and Mobility: Transnational Livelihood Strategies of the Somali Diaspora, Global Migration Perspectives, 9.

Human Development Report (2009), Overcoming Barriers: Human Mobility and Development, UNDP, New York: Palgrave Macmillan.

İçduygu, A. (1998), Thirty-seven Years After: Consequences of Emigration for Turkey, Paper presented at Migration Workshop, University of Essex, Brighton, June 9.

İçduygu, A. (2010), The Politics of Demography and International Migration: Implications for the EU-Turkey Relationship, Journal of Balkan and Near Eastern Studies, 12 (1), pp. 59-71.

Jennings, A; Clark, M. (2005), The Development Impact of Remittances to Nicaragua, Development in Practice, 15 (5), pp. 685-691.

Jones, R. C. (1998), Remittances and Inequality: A Question of Migration Stage and Geographic Scale, Economic Geography, 74 (1), pp. 8-25.

Keely, C.B.; Tran, B.N. (1989), Remittances from labour migration: evaluations, performance and implications, $I M R, 23$, pp. 500-525.

King R.; Ross, L. (2009), Finance and Growth: Schumpeter Might be Right, Quarterly Journal of Economics, 108, pp. 717-737.

Kireyev, A. (2006), The Macroeconomics of Remittances: the Case of Tajikistan, IMF Working Paper, Policy Development and Review Department. 
Kirwan, F. X. (1981), The Impact of Labor Migration on the Jordanian Economy, IMR, 15(4), pp. 671-695.

Koc, I.; Onan, I. (2004), International Migrants' Remittances and Welfare Status of the LeftBehind Families in Turkey, IMR, 38 (1), pp. 78-112.

Koechlin, V.; Leon, G. (2007), International Remittances and Income Inequality: An Empirical Investigation, Journal of Economic Policy Reform, 10 (2), pp. 124-141.

Lindley, A. (2004), Book Review on Poter D. Little (2003) Somalia: Economy without State, Oxford: James Currey.

Maimbo, S. R.; Rartha, D. (2005), Remittances, in: Maimbo, SR. and Rahta, D. (eds), Remittances Development Impacts and Future Prospects, Washington: The World Bank, pp.1-16.

Massey, D. S.; Arango, J.; Hugo, G.; Kouaouci, A.; Pellegrino, A.; Taylor, E. (1993), Theories of International Migration: A Review and Appraisal. Population and Development Review, 19 (3), pp. 431-466.

Marfleet, P. (2006), Refugees in a Global Era, Hampshire and New York: Palgrave McMilian.

Marfouk, A.; Docquier, F. (2006), International migration by education attainment, 19902000, in: C.Ozden and M.Schiff (eds), International Migration, Brain Drain and Remittances, New York: Palgrave Macmillan, pp. 151-99.

Martin, P.; Abella, M.; Midgley, E. (2004), Best Practices to Manage Migration: The Philippines, IMR, 38(4), pp. 1544-1560.

Milner, J. (2009), Refugees and the Regional Dynamics of Peacebuilding, Refugee Survey Quarterly, 28 (1), pp. 13-30.

Mughal, A.G. (2007), Migration, Remttances and Lving Standards in Tajikistan, IOM.

Nyberg-Sorenseon, N.; Van Hear, N.; Engberg-Pedersen, P. (2002), The MigrationDevelopment Nexus Evidence and Policy Options State-of-the-Art Overview, International Migration, 40 (5), pp. 3-47.

Olimova, S.; Bosc, I. (2003), Labor Migration from Tajikistan, Mission of the International Organization for Migration.

Orozco, M. (2002), Globalization and Migration: The Impact of Family Remittances in Latin America, Latin American Politics and Society, 44 (2), pp. 41-66.

Papademetriou, D. G. (1985), Emigration and Return in the Mediterranean Littoral, Comparative Politics, 18 (1), pp. 21-39.

Poirine, B. (1997), A Theory of Remittances as an Implicit Family Loan Arrangement, World Development, 25 (4), pp.589-611.

Ratha, D.; Mohapatra, S. (2007), Increasing the Macroeconomic Impact of Remittances on Development, Development Prospects Group the World Bank.

Ratha, D. (2007), Leveraging Remittances for Development, Policy Brief, Migration Policy Institute, Washington DC. Paper presented at the Leading Group on Solidarity Levies Conference on Innovative Finance, Oslo, February 6-7.

Ross, M. (2004), What Do We Know About Natural Resources and Civil War? Journal of Peace Research, 41 (3), pp. 337-356.

Sanderson, M. R.; Kenton, J. D. (2009), Globalization, Development and International Migration: A Cross-National Analysis of Less-Developed Countries, 1970-2000, Social Forces, 88 (1).

Sanderson, M. R. (2009), International Migration and Human Development: A CrossNational Analysis of Less-Developed Countries, 1970-2005, Social Indicators Research.

Sharma, B.; Gani, A. (2004), The Effects of Foreign Direct Investment on Human Development, Global Economy Journal, 4 (2), pp.1-18. 
Show, J. (2010). Making Housemaids Remittances Work for Low-Income Families in Sri Lanka, Development in Practice, 20 (1), pp. 18-30.

Skeldon, R. (2008), Migration and Development, UN/POP/EGM-MIG/2008/4.

Sriskandarajah, D. (2005), Migration and Development. A paper prepared for the Policy Analysis of Reseach Program of the GCIM available at www.gcim.org.

Stark, O.; Bloom, D. E. (1985), The New Economics of Labor Migration, The American Economic Review, 75 (2), pp. 173-178.

Taylor, J. E.; Arango, J.; Hugo, G.; Kouaouci, A.; Massey, D. S.; Pellegrino, A. (1996), International Migration and National Development, Population Index, 62 (2), pp. 181212.

UNDP (2006), Internationa Migration Report 2006: A Global Assesment, UN.

UNDP (2009), Human Development Report 2009: Overcoming barriers: Human mobility and development, available online at: http://hdr.undp.org/en/reports/global/hdr2009/.

World Bank 2009 Outlook for Remittance Flows 2009-2011, available online at: http://econ.worldbank.org/WBSITE/EXTERNAL/EXTDEC/EXTDECPROSPECTS/ 0, contentMDK:21121930 menuPK:3145470 pagePK:64165401 piPK:64165026 the SitePK:476883,00.html.

Yang, D. (2005), International Migration, Human Capital, and Entrepreneurship: Evidence from Philippine Migrants' Exchange Rate Shocks, World Bank Policy Research Working Paper, 3578. 


\section{Appendix 1. Tables}

Table 1. Effects of Remittances on HDI and GDP per capita Regression Results

\begin{tabular}{|c|c|c|c|c|c|c|}
\hline \multirow[t]{2}{*}{ Dependent Variable } & \multicolumn{2}{|c|}{ HDI at $\mathrm{t}+5$} & \multicolumn{4}{|c|}{ Percentage change in HDI } \\
\hline & (1) & $(2)$ & (3) & (4) & $(5)$ & (6) \\
\hline \multirow[t]{2}{*}{$\begin{array}{l}\text { WR/GDP } \\
\end{array}$} & 2.984 & 2.988 & $0.201 * *$ & $0.158 * * *$ & $0.146 * *$ & $0.168 * *$ \\
\hline & $(3.230)$ & $(3.278)$ & $(0.081)$ & $(0.056)$ & $(0.062)$ & $(0.076)$ \\
\hline \multirow[t]{2}{*}{ FDI/GDP } & 2.924 & 0.981 & 0.106 & 0.154 & 0.148 & 0.028 \\
\hline & $(3.778)$ & $(4.339)$ & $(0.083)$ & $(0.117)$ & $(0.119)$ & $(0.117)$ \\
\hline \multirow[t]{2}{*}{$\begin{array}{l}\text { ODA/GDP } \\
\end{array}$} & $-11.050 * * *$ & $-10.644 * * *$ & $0.151 * *$ & 0.126 & 0.109 & 0.109 \\
\hline & $(2.681)$ & $(2.657)$ & $(0.071)$ & $(0.090)$ & $(0.094)$ & $(0.097)$ \\
\hline \multirow[t]{2}{*}{ Public Exp. } & $15.519 * * *$ & $15.296 * *$ & $-0.470 * * *$ & $-0.375 * *$ & $-0.294 *$ & -0.249 \\
\hline & $(5.535)$ & $(6.508)$ & $(0.146)$ & $(0.176)$ & $(0.170)$ & $(0.224)$ \\
\hline \multirow[t]{2}{*}{ Conflict } & -10.762 & -8.392 & $-0.660 *$ & $-0.712 *$ & $-0.679 *$ & $-1.099 * *$ \\
\hline & $(11.127)$ & $(11.680)$ & $(0.340)$ & $(0.381)$ & $(0.378)$ & $(0.533)$ \\
\hline \multirow[t]{2}{*}{ democracy } & $12.797 * * *$ & $13.815^{* * *}$ & 0.008 & -0.013 & 0.018 & -0.095 \\
\hline & $(3.228)$ & $(3.118)$ & $(0.071)$ & $(0.073)$ & $(0.099)$ & $(0.079)$ \\
\hline \multirow[t]{2}{*}{ Population } & & -0.045 & & -0.002 & -0.002 & 0.011 \\
\hline & & $(0.549)$ & & $(0.011)$ & $(0.011)$ & $(0.012)$ \\
\hline \multirow[t]{2}{*}{ militrExp/GDP } & & -0.924 & & -0.000 & -0.046 & \\
\hline & & $(8.167)$ & & $(0.176)$ & $(0.184)$ & \\
\hline \multirow[t]{2}{*}{ Export/GDP } & & 1.099 & & -0.024 & -0.028 & \\
\hline & & $(0.966)$ & & $(0.029)$ & $(0.029)$ & \\
\hline \multirow[t]{2}{*}{ Emigration } & & 19.917 & & 1.386 & 1.134 & \\
\hline & & $(34.456)$ & & $(1.031)$ & 1.136 & \\
\hline \multirow[t]{2}{*}{ Braindrain } & & & & & & $0.055 * *$ \\
\hline & & & & & & $(0.027)$ \\
\hline \multirow[t]{2}{*}{ GNI per capita } & & & & & -0.000 & \\
\hline & & & & & $(0.000)$ & \\
\hline \multirow[t]{2}{*}{ _cons } & $595.891 * * *$ & $556.028 * * *$ & $6.279 * * *$ & $5.870 * *$ & $6.284 * *$ & $4.876 * *$ \\
\hline & $(43.650)$ & $(80.039)$ & $(1.218)$ & $(2.601)$ & $\begin{array}{l}(2.761) \\
\end{array}$ & $(2.223)$ \\
\hline R-squared & 0.632 & 0.616 & 0.211 & 0.184 & 0.168 & 0.169 \\
\hline $\mathrm{N}$ & 88 & 82 & 88 & 82 & 79 & 53 \\
\hline $\begin{array}{lll}* & \mathrm{p}<0.1 & * * \\
\end{array}$ & $\mathrm{p}<0.05$ & $\mathrm{p}<0.01$ & & & & \\
\hline
\end{tabular}

Table 2. The Effects of Remittances on HDI Observations Clustered by Human Development Level

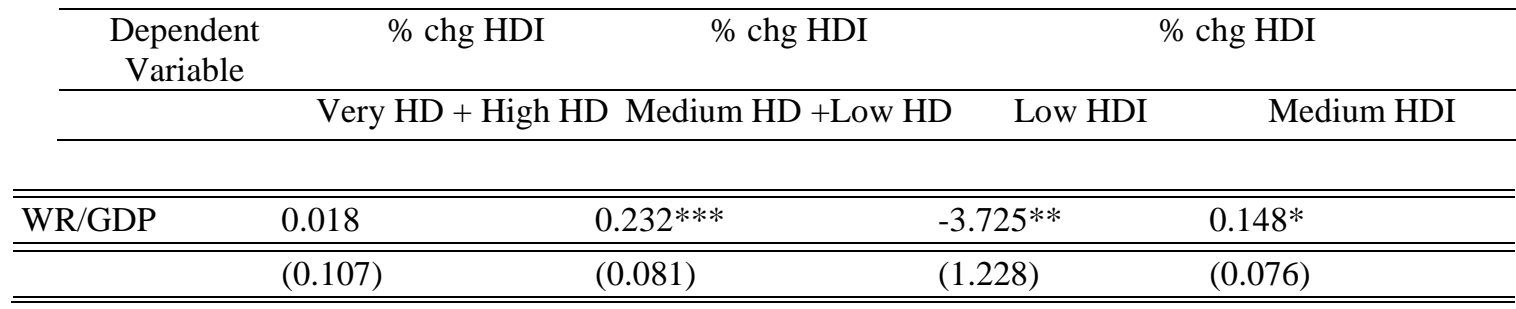




\begin{tabular}{|c|c|c|c|c|}
\hline \multirow[t]{2}{*}{ FDI/GDP } & -0.025 & 0.304 & 0.420 & $0.422 * *$ \\
\hline & $(0.017)$ & $(0.257)$ & $(1.500)$ & $(0.158)$ \\
\hline \multirow[t]{2}{*}{ ODA/GDP } & - & 0.150 & 0.244 & 0.051 \\
\hline & & $(0.091)$ & $(0.360)$ & $(0.067)$ \\
\hline \multirow[t]{2}{*}{ Public Exp. } & -0.091 & $-0.573 * *$ & -0.794 & $-0.621 * *$ \\
\hline & $(0.0839)$ & $(0.273)$ & $(3.143)$ & $(0.274)$ \\
\hline \multirow[t]{2}{*}{ conflict } & 0.194 & $-1.019 * *$ & $-2.542 * *$ & -0.383 \\
\hline & $(0.251)$ & $(0.561)$ & $(1.008)$ & $(0.257)$ \\
\hline \multirow[t]{2}{*}{ democracy } & - & 0.029 & 1.030 & $-0.193 * *$ \\
\hline & & $(0.091)$ & $(0.722)$ & $(0.085)$ \\
\hline \multirow[t]{2}{*}{ population } & -0.006 & 0.012 & 0.038 & 0.011 \\
\hline & $(0.004)$ & $(0.015)$ & $(0.084)$ & $(0.008)$ \\
\hline \multirow[t]{2}{*}{ militrExp/GDP } & $0.025^{*}$ & -0.177 & 0.894 & -0.017 \\
\hline & $(0.051)$ & $(0.310)$ & $(2.174)$ & $(0.262)$ \\
\hline \multirow[t]{2}{*}{ Export/GDP } & $0.020 * *$ & -0.046 & 0.038 & $-0.065^{*}$ \\
\hline & $(0.324)$ & $(0.035)$ & $(0.414)$ & $(0.034)$ \\
\hline \multirow[t]{2}{*}{ emigration } & $1.285 * * *$ & 1.660 & $10.032 * *$ & -0.745 \\
\hline & $(0.325)$ & $(1.491)$ & $(3.202)$ & $(1.153)$ \\
\hline \multirow[t]{2}{*}{ _cons } & $2.301 * * * *$ & $6.931 * *$ & $6.878 * *$ & $9.527 * * *$ \\
\hline & $(1,015)$ & $(2.897)$ & $(1.990)$ & $(2.234)$ \\
\hline R-squared & 0.254 & 0.162 & 0.165 & 0.389 \\
\hline $\mathrm{N}$ & 31 & 51 & 15 & 35 \\
\hline $\mathrm{p}<0.1$ & $6.878 * *$ & $9.527 * * *$ & $* * *$ & \\
\hline
\end{tabular}

Table 3. Basic Descriptive Statistics for Independent and Dependent Variables

\begin{tabular}{llllll}
\hline \hline Variable & Obs & Mean & Std. Dev. & Min & Max \\
\hline \hline HDI & 96 & 708.4583 & 187.292 & 306 & 956 \\
\hline \hline HDIperchg & 96 & 4.13875 & 5.293439 & -7.23 & 31.37 \\
\hline \hline PerChange in GDP perCap. PPP & 93 & 7.749462 & 11.2513 & -23.2 & 39.8 \\
\hline \hline GDP per capita & 93 & 7.725 & 11.9856 & .1 & 44.6 \\
\hline \hline Remittances & 93 & 2.533441 & 3.935648 & .01 & 23.1 \\
\hline \hline FDI & 95 & 3.018 & 8.705302 & 0 & 81.3 \\
\hline \hline ODA & 96 & 5.212917 & 9.783189 & 0 & 53.6 \\
\hline \hline Public Exp. On Healt and Edu & 92 & 6.544565 & 3.348786 & .5 & 15.4 \\
\hline \hline Conflict & 96 & .7395833 & 1.339637 & 0 & 6 \\
\hline \hline Democracy & 96 & 4.333333 & 5.695181 & -8 & 10 \\
\hline \hline Population & 96 & 34.63438 & 43.2935 & 1.3 & 174 \\
\hline \hline Military Expenditures & 89 & 2.719101 & 2.205307 & 0 & 13 \\
\hline \hline Export & 96 & 31.05208 & 19.66689 & 5 & 120 \\
\hline \hline Emigration & 96 & .5833333 & .4955946 & 0 & 1 \\
\hline \hline Braindr & 53 & 14.83585 & 16.19573 & 1.1 & 81.6 \\
\hline \hline GNI per capita PPP & 93 & 9069.032 & 9156.632 & 300 & 33740 \\
\hline \hline
\end{tabular}




\section{Appendix 2. Graphs}

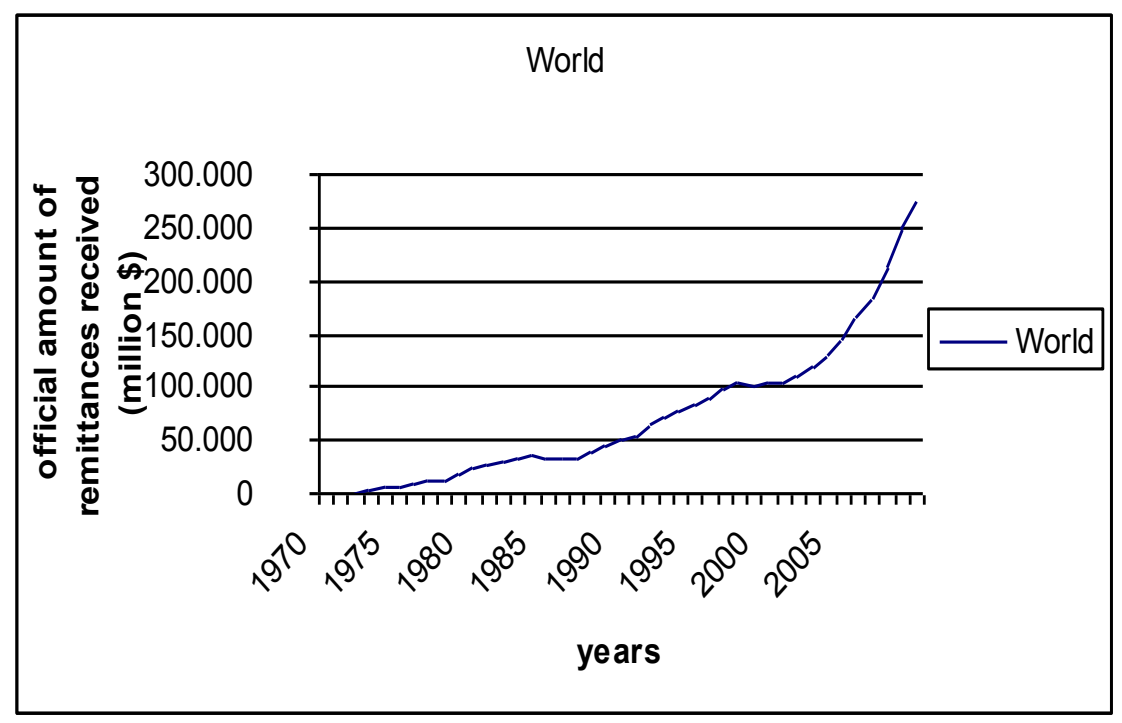

Graph 1. Total Inflow of Remittances between 1970-2008 Source: WB, 2009.

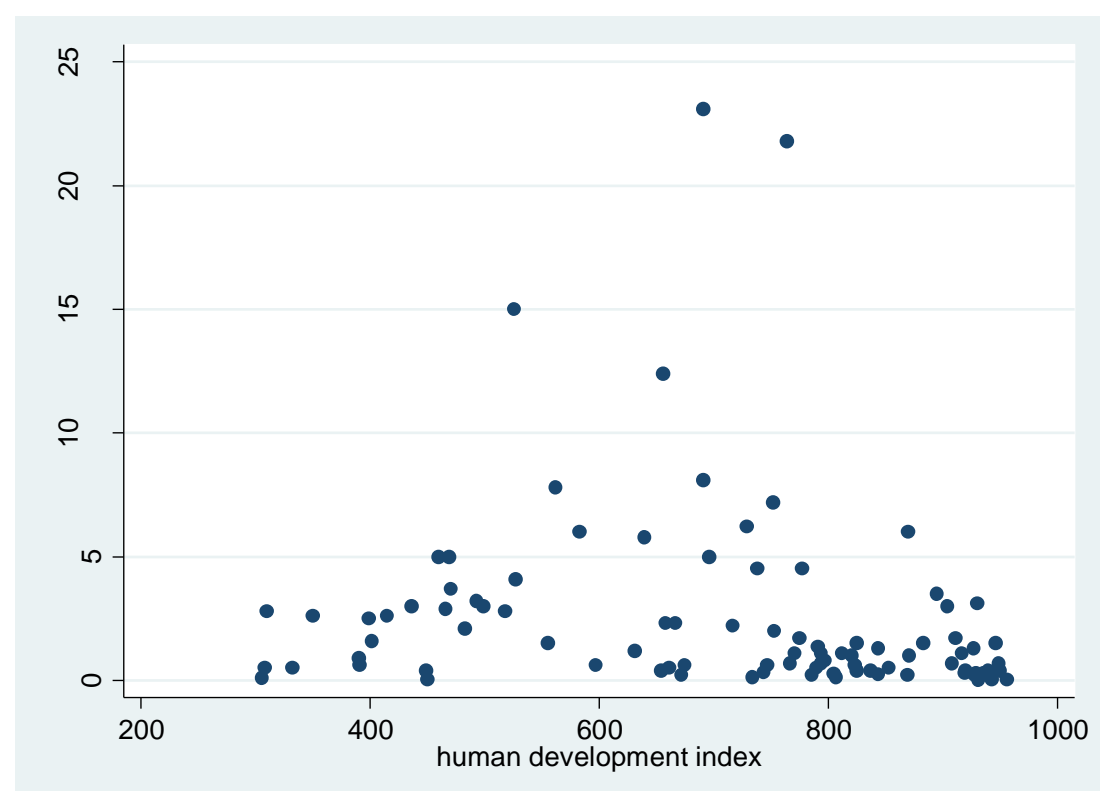

Graph 2. The Share of Remittances to GDP and HDI in the Dataset 


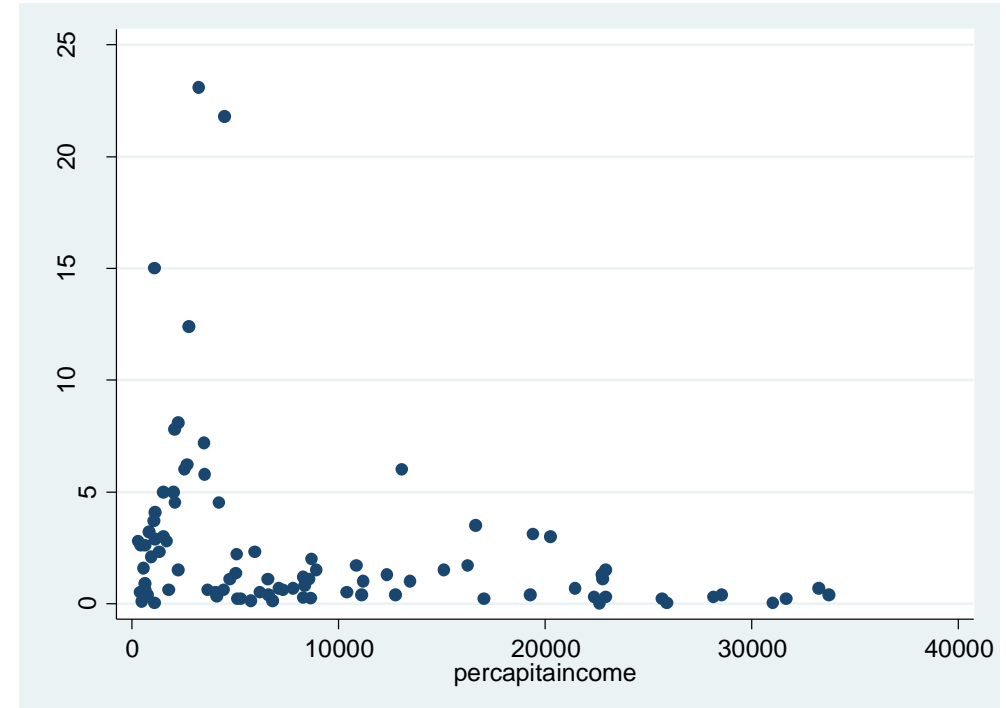

Graph 3. The Share of Remittances to GDP and GNI per capita (PPP) in the dataset

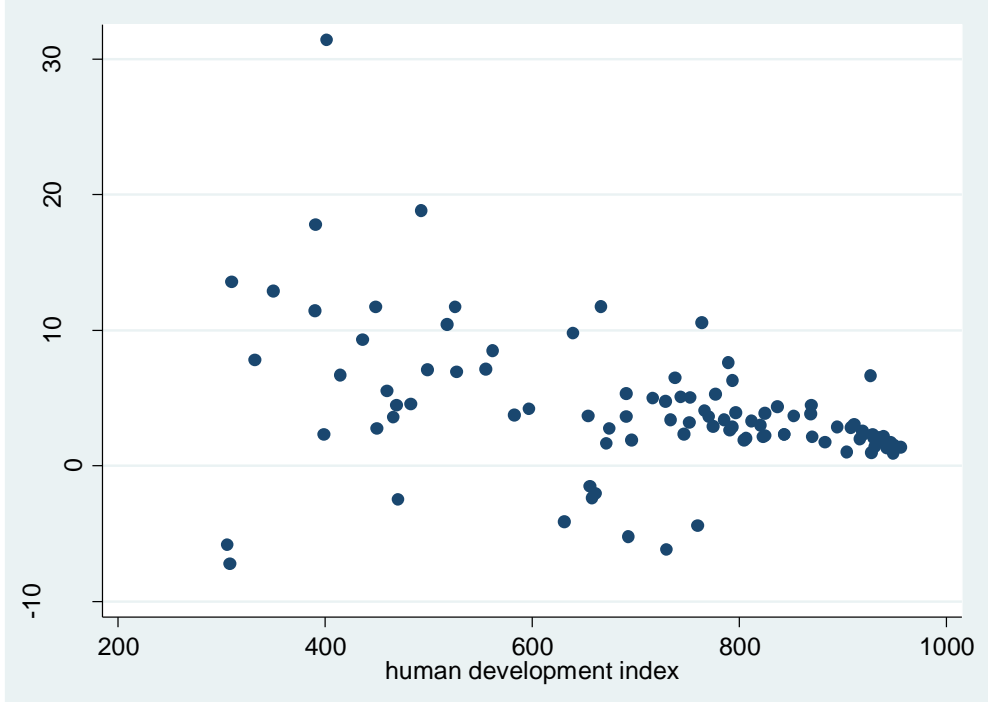

Graph 4. Human Development Level and Changes in HDI in the Dataset 